\title{
Urban Growth and Climate Change: Strategies for Effective Mitigation and Adaptation
}

\author{
H. Ranasinghe ${ }^{1 *}$, H. Gammanpila \\ ${ }^{I}$ Department of Forestry and Environmental Science, University of Sri Jayewardenepura, Sri Lanka \\ ${ }^{2}$ Toronto Regional Conservation Authority, Canada \\ *hemanthi.ranasinghe@gmail.com
}

\begin{abstract}
Between 1950 and 2030, the share of the world's population that lives in cities is predicted to grow from $30 \%$ to $60 \%$. This urbanization has consequences for the likelihood of climate change and for the social costs that climate change will impose on the world's quality of life. Cities are the engine of capitalist growth. Over time, people move from rural to urban areas as they seek a higher standard of living. In cities, people earn higher incomes and thus have the financial resources to purchase more consumption products ranging from private transportation to larger homes. Urbanization increases the demand for residential and commercial electricity consumption. Low and middle-income nations now have threequarters of the world's urban population. They also have most of the urban population at greatest risk from the increased intensity and/or frequency of storms, flooding, landslides and heat waves that climate change is bringing or will bring.
\end{abstract}

The need for action by Governments on climate-change adaptation is also urgent - and probably more urgent than that suggested by the IPCC's Fourth Assessment. This paper details the high adaptive and mitigative capacities which are infused into urban planning in planned cities using a case study from Toronto, Canada based on Toronto Green Standards. The main thrust areas highlighted in this paper are the development of innovative methods for reducing storm water flows thus reducing flood hazards, the use of advanced energy efficient technologies including renewable energies, development of innovative green spaces such as green roofs and designs that will reduce the urban heat island effect. The services provided by the provincial/municipal governments aided by the private sector in ensuring the protection of the urban populations and ecosystems from the adverse consequences of climate change are phenomenal in bringing on success; early warning for hazardous climatic events, rapid emergency response from the police, health service and fire services, all buildings conforming to building regulations and to health and safety regulations and served by piped water, sewers, all-weather roads, electricity and drains 24 hours a day. The cost of such infrastructure and services represents a small proportion of income for most citizens whether paid direct as service charges or within taxes. For the most part, most citizens engage very little in the management of these because it is assumed that government systems will ensure provision. However there are channels for complaints if needed - for instance local politicians or lawyers, ombudsmen, consumer groups and watchdogs. Thus, the vast majority of urban dwellers are protected from extreme weather without them having to engage in the institutions that ensure such protection. In addition to these there are other measures such as carbon pricing/taxes, incentives for green lifestyles etc. adopted to motivate people to reduce global warming emissions.

Keywords: Urban planning, Urban growth, Climate change mitigation, Climate change adaptation, Green standards

Proceedings of the International Forestry and Environment Symposium 2015 of the Department of Forestry and Environmental Science, University of Sri Jayewardenepura, Sri Lanka 